\title{
Ascorbic acid alters cell fate commitment of human neural progenitors in a WNT/ $\beta$ - catenin/ROS signaling dependent manner
}

Tareck Rharass ${ }^{1,2,6^{*}}$ (D), Margareta Lantow ${ }^{3}$, Adam Gbankoto ${ }^{4}$, Dieter G. Weiss ${ }^{3}$, Daniela Panáková2, and Stéphanie Lucas ${ }^{1}$

\begin{abstract}
Background: Improving the neuronal yield from in vitro cultivated neural progenitor cells (NPCs) is an essential challenge in transplantation therapy in neurological disorders. In this regard, Ascorbic acid (AA) is widely used to expand neurogenesis from NPCs in cultures although the mechanisms of its action remain unclear. Neurogenesis from NPCs is regulated by the redox-sensitive WNT/ $\beta$-catenin signaling pathway. We therefore aimed to investigate how AA interacts with this pathway and potentiates neurogenesis.

Methods: Effects of $200 \mu \mathrm{M}$ AA were compared with the pro-neurogenic reagent and WNT/ $\beta$-catenin signaling agonist lithium chloride (LiCl), and molecules with antioxidant activities i.e. $N$-acetyl-L-cysteine (NAC) and ruthenium red (RuR), in differentiating neural progenitor ReNcell VM cells. Cells were supplemented with reagents for two periods of treatment: a full period encompassing the whole differentiation process versus an early short period that is restricted to the cell fate commitment stage. Intracellular redox balance and reactive oxygen species (ROS) metabolism were examined by flow cytometry using redox and ROS sensors. Confocal microscopy was performed to assess cell viability, neuronal yield, and levels of two proteins: Nucleoredoxin (NXN) and the WNT/ $\beta$-catenin signaling component Dishevelled 2 (DVL2). TUBB3 and MYC gene responses were evaluated by quantitative real-time PCR. DVL2-NXN complex dissociation was measured by fluorescence resonance energy transfer (FRET).

Results: In contrast to NAC which predictably exhibited an antioxidant effect, AA treatment enhanced ROS metabolism with no cytotoxic induction. Both drugs altered ROS levels only at the early stage of the differentiation as no changes were held beyond the neuronal fate commitment stage. FRET studies showed that AA treatment accelerated the redox-dependent release of the initial pool of DVL2 from its sequestration by NXN, while RuR treatment hampered the dissociation of the two proteins. Accordingly, AA increased WNT/B-catenin signaling output i.e. MYC mRNA level, whereas RuR attenuated it. Moreover, AA improved neurogenesis as much as LiCl as both TUBB3-positive cell yield and TUBB3 mRNA level increased, while NAC or RuR attenuated neurogenesis. Markedly, the neurogenesis outputs between the short and the full treatment with either NAC or AA were found unchanged, supporting our model that neuronal yield is altered by events taking place at the early phase of differentiation.
\end{abstract}

(Continued on next page)

\footnotetext{
* Correspondence: tareck.rharass@yahoo.fr

${ }^{1}$ Physiopathology of Inflammatory Bone Diseases, University of the Littoral Opal Coast, F-62327 Boulogne sur Mer, France

2Electrochemical Signaling in Development and Disease, Max Delbrück

Center for Molecular Medicine in the Helmholtz Association, D-13125 Berlin,

Germany

Full list of author information is available at the end of the article
} 
(Continued from previous page)

Conclusions: Our findings demonstrate that AA treatment elevates ROS metabolism in a non-lethal manner prior to the NPCs commitment to their neuronal fate. Such effect stimulates the redox-sensitive DVL2 activation and WNT/ $\beta$ catenin signaling response that would enhance the ensuing neuronal cell differentiation.

Keywords: Ascorbic acid, Dishevelled, N-acetyl-L-cysteine, Neural progenitors, Neuronal differentiation, Nucleoredoxin, Reactive oxygen species, Redox state, WNT/ $\beta$-catenin signaling

\section{Background}

In the last decades, much effort has been made to overcome issues in clinical potential application of human central nervous system (CNS) precursors for transplantation in neurological diseases $[1,2]$. One potent therapy consists in the use of in vitro expanded neural progenitor cells (NPCs) [3]. Precursor cells from rat embryonic ventral mesencephalon can be expanded in vitro and differentiated into dopaminergic neurons whose transplantation in hemiparkinsonian rats results in a functional recovery [4]. In addition, the transplantation into Parkinsonian rats of human dopamine neurons derived from in vitro expanded midbrain precursors results in successful grafts [5]. The success of such therapies depends on the efficiency of in vitro generation of human dopamine neurons prior to the transplantation. Numerous reports emphasize the critical impact of a simple supplementation of the culture medium with ascorbic acid (AA); doses comparable to the physiologic extracellular levels in the brain [6] facilitate the large-scale production of dopaminergic neurons from CNS precursors ([7-18]; see Table 1). AA is an essential nutrient widely admitted as an antioxidant agent in vivo $[19,20]$, and playing a role as cofactor in various biochemical reactions of the cell metabolism [21]. Moreover, AA treatment not only affects CNS precursor differentiation but also enhances dopamine neuron conversion from human placentaderived mesenchymal stem cells [22], human blood embryonic stem cells [23] or adult rat skeletal musclederived stem cells [24], which suggests that AA could participate in the lineage cell commitment.

The mechanisms by which AA enhances neuronal differentiation of CNS precursors are still unclear. AA is found to change the responsiveness of genes regulating neuronal development and maturation as well as signaling pathways implicated in cell fate determination of mammal precursors [13, 15]. Importantly, AA-mediated NPCs dopaminergic differentiation is also found accompanied with an up-regulation of gene products implicated in reactive oxygen species (ROS) detoxification; such an increase in expression of antioxidant response genes has been attributed to AA pro-oxidant ability [15]. Indeed, the crucial role of ROS in the regulation of signaling pathways in many aspects of cell physiology including NPCs differentiation is well documented $[25,26]$.
However, the redox properties of AA are still controversial as both pro- and antioxidant effects are reported and mostly depend on the experimental conditions and models of the studies (see for reviews [20, 21]). Although no clear evidence on AA pro-oxidant effect has been provided so far in vivo, AA antioxidant role is discussed ex vivo in rat brain slices $[27,28]$ and in in vitro models as cultured human lymphocytes and lung cells [29, 30] and solutions [29-32]. So far, no clear evidence that AA acts as pro- or antioxidant to favor neuronal differentiation of NPCs have been provided since direct measurements of ROS levels are missing in all the reports stressing the positive role of AA in NPCs neurogenesis (see references in Table 1). Considering the important role that AA plays in the cellular metabolism, and that ROS are known to either induce cellular damage [33] or act as messengers regulating numerous redox events in many signaling pathways [25], elucidating the mechanisms by which AA improves the neuronal differentiation of CNS precursors remains an important challenge.

To address the relationship between AA effects on the ROS levels and the neuronal differentiation of NPCs, we used the immortalized human neural progenitor ReNcell VM cells that have been extensively characterized the last decade and have proved their reliability as in vitro NPC model. These cells are reported to promptly differentiate, in vitro, into glial cells and dopaminergic neurons within 2-3 days upon growth factors removal [34], and to commit to their neuronal fate within the first day of differentiation [26, 35]. Obviously, investigating the effects of AA implies to take into account that its activities depend on two main factors as all the pharmacological drugs. First, AA activities depend on the initial dosage of the reagent; we focused our investigations on the effects of the compound at the physiological relevant dose of $200 \mu \mathrm{M}$ [6] to stay in agreement with the concentration range used in the previous studies on cultivated CNS precursors (Table 1). Second, AA effects also depend on its administration period that influences the time required for the compound to accumulate within the cells and to initiate the mechanisms implicated with its redox activity. Accordingly, we ensured that AA redox activity takes place during the beginning of the differentiation phase by supplementing the reagent to the cells $24 \mathrm{~h}$ prior to the differentiation was initiated 
Table 1 Overview of reports stressing that AA ameliorates the neuronal differentiation from NPC progenitors

\begin{tabular}{|c|c|c|c|}
\hline NPC models & Differentiation factors & Enhanced effects & Refs. \\
\hline Rat embryonic mesencephalic cell cultures & $200 \mu \mathrm{M} A \mathrm{~A}$ & $\begin{array}{l}\text {-Glial differentiation } \\
\text {-Neurite growth } \\
\text {-Dopamine neurons }\end{array}$ & [7] \\
\hline Mouse embryonic stem cells & $200 \mu \mathrm{M} A \mathrm{~A}+\mathrm{SHH}+\mathrm{FGF} 8$ & $\begin{array}{l}\text {-Dopamine neurons } \\
\text {-Serotonin neurons }\end{array}$ & [8] \\
\hline $\begin{array}{l}\text { Long-term basic fibroblast growth factor } \\
\text { expanded rat mesencephalic precursors }\end{array}$ & $100 \mu \mathrm{M} \mathrm{AA}$ & -Dopamine neurons & [9] \\
\hline Mouse embryonic stem cells & $200 \mu \mathrm{M} \mathrm{AA}+\mathrm{SHH}+\mathrm{FGF} 8$ & -Dopamine neurons & [10] \\
\hline $\begin{array}{l}\text { Nurr1-transfected rat embryonic cortical } \\
\text { progenitors }\end{array}$ & $200 \mu \mathrm{M} A \mathrm{~A}+\mathrm{B} 27$ & -Dopamine neurons & [11] \\
\hline Rat embryonic cortical precursors & $200 \mu \mathrm{M} A \mathrm{~A}$ & $\begin{array}{l}\text {-Astrocyte differentiation } \\
\text {-Neuronal differentiation } \\
\text { and maturation }\end{array}$ & [12] \\
\hline Mouse ventral mesencephalic precursors & $200 \mu \mathrm{M} A \mathrm{~A}$ & $\begin{array}{l}\text {-Astrocyte differentiation } \\
\text {-Dopamine neurons } \\
\text {-Gene responses related } \\
\text { to cell fate determination, } \\
\text { neuron development and } \\
\text { maturation }\end{array}$ & [13] \\
\hline $\begin{array}{l}\text { bFGF/SHH-stimulated rat ventral } \\
\text { mesencephalic precursors }\end{array}$ & $200 \mu \mathrm{M} A \mathrm{~A}$ & -Dopamine neurons & [14] \\
\hline Rat ventral mesencephalic precursors & $200 \mu \mathrm{M} A \mathrm{~A}$ & $\begin{array}{l}\text {-Dopamine neurons } \\
\text {-Gene responses related to } \\
\text { dopamine neuron marker, } \\
\text { ROS response mediators } \\
\text { and trophic factors }\end{array}$ & [15] \\
\hline Mouse embryonic stem cells & $200 \mu \mathrm{M} A A+S H H+F G F 8 b$ & -Dopamine neurons & [16] \\
\hline Rat ventral mesencephalic precursors & $100 \mu \mathrm{M} \mathrm{AA}$ & $\begin{array}{l}\text {-Dopamine neurons } \\
\text {-Graft survival }\end{array}$ & [17] \\
\hline $\begin{array}{l}\text { Long-term expanded human fetal midbrain } \\
\text { and cortical precursor cultures }\end{array}$ & $\begin{array}{l}200 \mu \mathrm{M} A \mathrm{~A}+\text { low } \mathrm{O}_{2}+\text { longer } \\
\text { diff. time }\end{array}$ & $\begin{array}{l}\text {-Neuronal yield } \\
\text {-Dopamine neurons }\end{array}$ & [18] \\
\hline
\end{tabular}

$A A$ : Ascorbic acid

SHH: Sonic hedgehog

FGF8: Fibroblast growth factor 8

bFGF: Basic fibroblast growth factor

and simultaneously with the induction of the differentiation. We then compared its effects with molecules well recognized for either their pro-neurogenic or antioxidant activity.

First, to elucidate the nature and the time range of AA redox properties we monitored the kinetics of both intracellular redox balance and ROS metabolism. Kinetics were performed from the first hours of the differentiation i.e. a redox-sensitive period found to modulate the neurogenesis [26], up to 1 day i.e. after the cell fate commitment phase. Second, to verify AA effect on neurogenesis we quantified the neuronal yield and assessed the gene expression level of a specific neuronal marker. Two periods of treatment were compared to clarify whether the neurogenic effect of AA happens during the cell fate commitment stage and/or after cells committed to their fate. Thus, the cell exposure to AA was either continuous up to the third day of differentiation or interrupted after the first day. Finally, to connect the redox activity of AA with its neurogenic effect we investigated how the reagent influences the response of the $\mathrm{WNT} / \beta$-catenin signaling pathway. Since its activation is a pre-requisite for the neuronal differentiation of ReNcell VM cells $[26,36]$, and since its output is modulated by ROS during the cell fate commitment period $[26,35]$, we hypothesized that this pathway may play a key role in AA effects. Here, our findings reveal that AA treatment results in a non-lethal pro-oxidant effect in in vitro differentiated human NPCs and that it enhances ROS metabolism strictly during the cell fate commitment period. Our data also indicate that AA treatment enhances both the $\mathrm{WNT} / \beta$-catenin signal transduction and the neuronal differentiation. Finally, they show that AA treatment facilitates the redox-sensitive dissociation of complexes made of two proteins [26, 37]: Nucleoredoxin $(\mathrm{NXN})$ that is an endogenous antioxidant ubiquitously expressed in the cells [38]; and Dishevelled segment polarity protein 2 (DVL2), an essential upstream mediator 
of the $\mathrm{WNT} / \beta$-catenin pathway [39] which relays the signal further downstream once its initial inactive pool is released from sequestration by NXN [26]. Altogether, our results infer that AA treatment potentiates the neuronal fate commitment of NPCs by increasing the ROS metabolism which enhances the redox-dependent $\mathrm{WNT} / \beta$-catenin signaling output. Accordingly, our study supports the beneficial AA supplementation at physiological doses for improving the in vitro neuronal yield of human NPCs that are aimed at cell replacement and regenerative therapies in the treatment of neuronal disorders.

\section{Methods}

\section{Cell culture}

Experiments were conducted in the immortalized human neural progenitor ReNcell VM cells derived from the ventral midbrain of a 10-week human fetal neural tissue (Merck Millipore, Billerica, MA, USA). Cells are cultivated in flasks pre-coated with Cultrex Mouse Laminin I (Trevigen, Gaithersburg, Germany), in proliferating medium containing DMEM/F12 medium, B27 neural cell supplement, L-glutamine, gentamycin, human basic fibroblast growth factor (all from Invitrogen, Karlsruhe, Germany), human epidermal growth factor and heparin (all from Sigma-Aldrich, Steinheim, Germany) as described previously [34,36]. When $80 \%$ cell confluence is reached, differentiation is induced by discarding the proliferating medium followed by washing steps and replacement with differentiating medium i.e. medium without growth factors.

\section{Cell treatment}

Proliferating and/or differentiating cells were treated with $5 \mu \mathrm{M}$ phorbol 12-myristate 13-acetate (PMA), $200 \mu \mathrm{M}$ ascorbic acid (AA), $5 \mathrm{mM} N$-acetyl- $L$-cysteine (NAC), $1 \mathrm{mM}$ hydrogen peroxide $\left(\mathrm{H}_{2} \mathrm{O}_{2}\right), 15 \mathrm{mM}$ lithium chloride $(\mathrm{LiCl})$ or $0.5 \mu \mathrm{M}$ ruthenium red (RuR) (all from Sigma-Aldrich). Different time ranges for cell treatments were applied. $\mathrm{H}_{2} \mathrm{O}_{2}$ or PMA were used as positive controls for redox state and ROS detections, and were added to untreated proliferating cells for $1 \mathrm{~h}$ or $24 \mathrm{~h}$, respectively. AA or NAC were added to untreated proliferating cells for $24 \mathrm{~h}$. Then, the cell differentiation was initiated and the AA-pre-treated- and NAC-pre-treated cells were respectively exposed to AA or NAC for two periods: a long period that corresponds to a drug exposure along the $72 \mathrm{~h}$ of differentiation (i.e. full treatment); a shorter one that consists in a drug exposure for the first $24 \mathrm{~h}$ of differentiation followed by an incubation of the cells in drug-free differentiating medium for the next $48 \mathrm{~h}$ (i.e. short treatment). $\mathrm{LiCl}$ or $\mathrm{RuR}$ were added to untreated proliferating cells for $1 \mathrm{~h}$. Then a further exposure of the cells to $\mathrm{LiCl}$ for $24 \mathrm{~h}$ or to $\mathrm{RuR}$ for $2 \mathrm{~h}$ was performed at the onset of the differentiation process, followed by an incubation of the cells in drugfree medium up to the third day of differentiation. RuR effect was also examined for a full treatment along the $72 \mathrm{~h}$ of differentiation.

\section{Flow cytometry}

Intracellular redox state and ROS levels were assessed through flow cytometry using the redox indicator 5(6)carboxy-2 ${ }^{\prime}, 7^{\prime}$-dichlorodihydrofluorescein diacetate (carboxy- $\mathrm{H}_{2} \mathrm{DCFDA}$ ) (Invitrogen) and the ROS indicator dihydrorhodamine 123 (DHR123) (Sigma-Aldrich), respectively [40]. Cells were stained with $10 \mu \mathrm{M}$ carboxy$\mathrm{H}_{2}$ DCFDA for $1 \mathrm{~h}$ or with $1 \mu \mathrm{M}$ DHR123 for $0.5 \mathrm{~h}$ at $37{ }^{\circ} \mathrm{C}, 5 \% \mathrm{CO}_{2}$, in the dark. After rinsing with prewarmed culture medium, a further incubation of the carboxy- $\mathrm{H}_{2}$ DCFDA stained-cells for $0.5 \mathrm{~h}$ was performed to allow the diacetate group of the probe being hydrolyzed by cellular esterases and to render the probe sensitive to oxidation according to the manufacturer's instructions. Cells were then placed in HBSS complemented with $14 \mathrm{mM}$ HEPES and $0.9 \% \mathrm{NaCl}$ (all from Carl Roth, Karlsruhe, Germany) prior measurements. Mean fluorescence intensities in a total of $10^{4}$ cells were determined in each sample using EPICS XL-MCL flow cytometer system (Beckman Coulter). An unstained cell sample was carried along as a control for autofluorescence. Data were analyzed for 4 independent exposure experiments measured in duplicates. Results are shown as means \pm SD a.u. (arbitrary units).

\section{Immunocytochemistry}

Cells grown on glass coverslips pre-coated with poly-Dlysine then with laminin were fixed $20 \mathrm{~min}$ with $4 \%$ paraformaldehyde and 4\% sucrose in PBS followed by 10 min quenching with $50 \mathrm{mM} \mathrm{NH}_{4} \mathrm{Cl}$ and $5 \mathrm{~min}$ permeabilization with $0.2 \%$ Triton-X100 (all from Sigma-Aldrich). Non-specific binding sites were blocked $1 \mathrm{~h}$ with $1 \%$ gelatin (Sigma-Aldrich). Cells were incubated $1 \mathrm{~h}$ with the following primary antibodies: mouse anti-glial fibrillary acidic protein-Cy3-conjugate (i.e. anti-GFAP; dilution 1:400) (Sigma-Aldrich, Cat\# C9205); mouse anti-tubulin, beta 3 class III-FITC-conjugate (i.e. anti-TUBB3; dilution 1:80) (Abcam, Cat\# ab25770); rabbit anti-dishevelled segment polarity protein 2 (i.e. anti-DVL2; dilution 1:200) (Santa Cruz Biotechnology, Cat\# sc-13974); goat anti-nucleoredoxin (i.e. anti-NXN; dilution 1:200) (Santa Cruz Biotechnology, Cat\# sc161973). When required, cells were rinsed with $0.2 \%$ gelatin and incubated 45 min with anti-rabbit Alexa Fluor 488 or anti-goat Alexa Fluor 594 secondary antibodies (all from Invitrogen; dilution 1:500); then to prevent any dissociation of the secondary antibodies an additional post-fixation step (10 min with $2 \%$ paraformaldehyde and $2 \%$ sucrose) was carried out, followed by a 
quenching step ( 5 min with $50 \mathrm{mM} \mathrm{NH}_{4} \mathrm{Cl}$ ). Nuclei were stained $10 \mathrm{~min}$ with $2 \mu \mathrm{M}$ Hoechst 32258 (Sigma-Aldrich). Coverslips were mounted using prolong gold antifade reagent (Invitrogen).

\section{Confocal microscopy and quantitative image analysis}

Neuronal cell differentiation imaging was performed using LSM 710 NLO confocal microscope system (Carl Zeiss). Fluorescent images of DVL2 and NXN proteins were acquired with TCS SP2 AOBS confocal laser scanning microscope (Leica). The parameter settings (detector gain and offset, pinhole size at 1 arbitrary unit, laser power, confocal section, zoom factor, frame averaging) were kept constant for all comparative set of experiments. With these settings no photobleaching was detected after several repeated measurements on the same microscopic field. Brightness/contrast adjustments were applied equally to every pixel in the images (i.e. maximum projections), for each comparative set (e.g. control vs. treatment) using Fiji/ImageJ. Adjustments were performed on individual color channels before merging images. No change to gamma settings was applied. For neuron quantitation, TUBB3-positive cells were counted and the neuronal yield was calculated as \% of the population from the ratio between TUBB3positive cells and Hoechst-stained cells (i.e. whole cell population). For quantification of protein amounts, regions of interest were set for each cell in the images based on cell boundaries and mean fluorescence intensities were measured. The background fluorescence was subtracted for each image and values were then normalized. For each time point or treatment condition, at least 10 images per experiment were recorded for both neuron counting and protein level quantification experiments. Data are shown as means \pm SD from 3 independent experiments.

\section{Cell viability assay}

Cell density was quantified to assess cytotoxicity following the different treatments. For each treatment condition, proliferating cells were seeded on glass coverslips pre-coated with poly-D-lysine and laminin at the same cell concentration. Cell differentiation was induced up to 3 days when the cell confluency reached $\sim 80 \%$. Then, cells were loaded with $2 \mu \mathrm{M}$ Hoechst 32258 for $10 \mathrm{~min}$ followed by 2 washing steps with PBS. Coverslips were fixed and mounted as described above and images of nuclei were acquired with LSM 710 NLO confocal microscope. Nuclei were counted using Fiji/ImageJ software to determine the residual cell density. The nuclear labelling reports the number of cells in the population. Cells were treated with $\mathrm{AA}, \mathrm{LiCl}, \mathrm{RuR}$ or NAC as aforementioned. Images were acquired for proliferating cells treated for $24 \mathrm{~h}$ with AA, and after $72 \mathrm{~h}$ of differentiation. About 10 images per experiment were captured for each condition. Data were obtained from 3 independent experiments and presented as means (\% of cell viability) \pm SD.

\section{Fluorescence resonance energy transfer (FRET)}

FRET microscopy was performed to assess physical binding between DVL2 and NXN proteins. FRET was measured with the sensitized emission method [41] using TCS SP2 AOBS confocal microscope as previously described [26], and the parameter settings were kept constant throughout all experiments. Different set of cell specimens were prepared to get the fully corrected FRET signal [42]: a FRET specimen consisting in a cell sample labeled with both the donor (Alexa Fluor 488-labeling DVL2) and the acceptor (Alexa Fluor 594-labeling NXN), and from which the FRET signal can be detected; and reference specimens labeled with the donor only and the acceptor only to obtain calibration coefficients required for adequate corrections of direct acceptor excitation and donor emission bleed-through. The excitation wavelengths were set at $488 \mathrm{~nm}$ and $594 \mathrm{~nm}$ for the donor and the acceptor, respectively. The detection wavelength ranges were set at $490-550 \mathrm{~nm}$ for the donor to avoid leakage of acceptor fluorescence into the donor image, and at $620-700 \mathrm{~nm}$ for the acceptor. The acquisition method of the FRET signal included suitable sequential laser switching-on to enable selective excitation of one fluorophore, and meanwhile avoid the inappropriate excitation of the other one. Once FRET signal was acquired and corrected, the proportion of direct protein-protein association i.e. FRET efficiency (FRE$\mathrm{T}_{\text {eff }}$ ), was calculated using Eq. (1) [43]:

$$
\mathrm{FRET}_{\text {eff }}=[\mathrm{B}-\mathrm{A} \times \beta-\mathrm{C} \times(\gamma-\alpha \times \beta)] /[\mathrm{C} \times(1-\beta \times \delta)]
$$

Where $\mathrm{A}, \mathrm{B}$ and $\mathrm{C}$ correspond to the intensities of the donor, the FRET (i.e. acceptor indirectly excited by the donor excitation) and the acceptor (i.e. acceptor selectively excited) signals, respectively, acquired from the FRET specimen. $\alpha, \gamma$ and $\delta$ consist in the calibration factors calculated from the reference specimen labeled with the acceptor only: $\alpha=\mathrm{A} / \mathrm{C}, \gamma=\mathrm{B} / \mathrm{C}, \delta=\mathrm{A} / \mathrm{B}$. $\beta$ is a calibration factor obtained from the specimen labeled with the donor only: $\beta=B / A$. FRET eff $_{\text {were measured inside }}$ individual cells $(\mathrm{n}=\sim 50$ cells per time point) for every condition. Measurements were performed for 3 independent experiments, and results are presented as means $\left(\%\right.$ of $\left.\mathrm{FRET}_{\text {eff }}\right) \pm \mathrm{SD}$.

\section{Quantitative real-time polymerase chain reaction (qPCR)} Total RNAs were extracted with high pure RNA isolation kit (Roche, Mannheim, Germany) according to the manufacturer's instructions. Residual contaminating 
genomic DNA was digested by DNase I recombinant, RNase-free (Roche). cDNA synthesis was primed with oligo(dT)18 primers and generated from $1 \mu \mathrm{g}$ template RNA with M-MuLV RT using first strand cDNA synthesis kit (Thermo Scientific, Karlsruhe, Germany) as following: $5 \mathrm{~min}$ at $25^{\circ} \mathrm{C}, 60 \mathrm{~min}$ at $37^{\circ} \mathrm{C}$ and $5 \mathrm{~min}$ at $70{ }^{\circ} \mathrm{C}$. Real-time PCR analysis was performed by mixing 100 ng template cDNA with TaqMan gene expression master mix and following TaqMan gene expression assays (all from Applied Biosystems, Darmstadt, Germany): MYC (Hs00153408_m1); TUBB3 (Hs008 01390_s1); RPL13A (Hs04194366_g1). Contents were transferred into 96-well PCR plates (Thermo Scientific) as the final concentration of cDNA in each well was $5 \mathrm{ng} / \mu \mathrm{l}$. Amplifications were performed using iQ5 realtime PCR detection system (Bio-Rad) as following: $2 \mathrm{~min}$ at $50{ }^{\circ} \mathrm{C}$ for activation of the Uracil-N-Glycosylase; $10 \mathrm{~min}$ at $95{ }^{\circ} \mathrm{C}$ for polymerase activation; 40 repeats of two-step cycling $\left(15 \mathrm{~s}\right.$ at $95{ }^{\circ} \mathrm{C}$ for denaturation and $1 \mathrm{~min}$ at $60{ }^{\circ} \mathrm{C}$ for annealing and extension). Relative expression values were obtained by normalizing $\mathrm{Ct}$ values of the tested genes in comparison with $\mathrm{Ct}$ values of ribosomal protein L13a (RPL13A, housekeeping gene) using the $\Delta \mathrm{Ct}$ method. Each condition was assessed from 3 independent samples in duplicate. Results are presented as fold induction means \pm SD from 3 independent experiments.

\section{Statistics}

Statistical analyses were performed using two-tailed unpaired Student's t-test with GraphPad Prism 6. ${ }^{*} P \leq 0.05$, significantly different compared to the control (untreated proliferating cells i.e. $t=0 \mathrm{~h}$ of differentiation). ${ }^{\#} P \leq 0.05$, significantly different between samples at each time point. Data are presented as means \pm SD and averaged from at least 3 independent experiments.

\section{Results}

AA treatment increases the intracellular ROS levels strictly during a narrow time range at the onset of human NPCs differentiation

AA is reported to augment neurogenesis of mammalian CNS precursors in vitro (Table 1); yet whether it displays pro-oxidant or antioxidant effects remains uncertain. We therefore addressed this issue in differentiating ReNcell VM cells treated with the physiological dose of $200 \mu \mathrm{M}$ of AA [6]; the cells were even pre-treated for $24 \mathrm{~h}$ before the induction of the differentiation to ensure that AA redox activity can take place at the onset of the differentiation process. We first examined the cellular redox balance by flow cytometry during the first $3 \mathrm{~h}$ of differentiation and after the cells committed to their fate (i.e. at $24 \mathrm{~h}$ ) with the redox indicator carboxy$\mathrm{H}_{2}$ DCFDA [40]. Changes in the fluorescent signal level are clearly linked to the redox balance as shown with the increase triggered by the pro-oxidant reagent phorbol 12-myristate 13-acetate (PMA) [44] in proliferating cells treated for $24 \mathrm{~h}$ (Fig. 1a). In untreated cells, inducing the differentiation by growth factors removal led to an increased fluorescent signal from $1 \mathrm{~h}$ that remained stable up to $2 \mathrm{~h}$ and returned to baseline at $3 \mathrm{~h}$ (Fig. $1 \mathrm{~b}$ ). These data confirm the switch in the redox state at the early phase of human NPCs differentiation [26]. The signal even decreased below the baseline at $24 \mathrm{~h}$ (Fig. 1b), indicating that the physiological metabolism of the cells changed and corroborating that cells committed to different fates. Surprisingly, 24 h-pre-treatment of proliferating cells with AA did not affect the cellular redox state as the fluorescent signal stayed at baseline (Fig. 1b; $t=$ $0 \mathrm{~h}$ ). Importantly, AA treatment led to a pro-oxidant effect only during the narrow time range of the first $3 \mathrm{~h}$ of differentiation. The signal increased at $1 \mathrm{~h}$ and was $40 \%$ higher than for untreated cells (Fig. 1b; 1.9 a.u. for AAtreated cells vs. 1.3 a.u. for untreated cells). Then, the

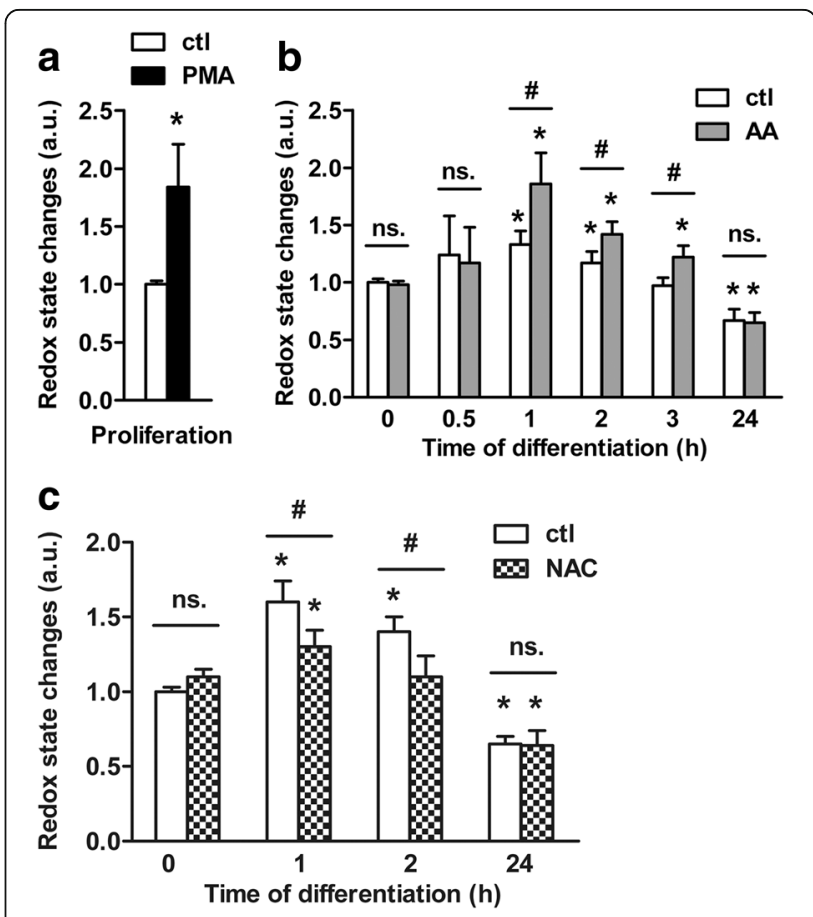

Fig. 1 AA treatment alters the cellular redox balance at the onset of differentiation. a Changes in the intracellular redox state measured by flow cytometry in proliferating cells. Cells were treated with $5 \mu \mathrm{M}$ PMA (positive control). $\mathbf{b}$ Intracellular redox state was assessed up to $24 \mathrm{~h}$ after the differentiation was induced. Data are compared between untreated differentiating cells and differentiating cells treated with $200 \mu \mathrm{M}$ AA only up to $24 \mathrm{~h}$ post-differentiation. c Changes in intracellular redox state measured in untreated differentiating cells were compared with values obtained for differentiating cells treated with 5 mM NAC only up to $24 \mathrm{~h}$ post-differentiation. $n=\sim 3.10^{4}$ cells per time point. Values are mean \pm SD of three independent experiments. ${ }^{*} P \leq 0.05$ compared with untreated differentiating cells at $t=0 \mathrm{~h} ;{ }^{\#} P \leq 0.05$ between each treatment condition at each time point; ns, non-significant 
signal decreased after $3 \mathrm{~h}$ in AA-treated cells but still remained significantly higher than the baseline. After the cell fate commitment stage, AA did not affect the redox balance anymore as the signal at $24 \mathrm{~h}$ was as diminished as the one for untreated cells. Next, we assessed the effect of the potent stoichiometric ROS scavenger $\mathrm{N}$ acetyl- $L$-cysteine (NAC) [45] on the NPCs. Untreated cells were incubated with NAC only according to a time exposure similar to AA i.e. a $24 \mathrm{~h}$-pre-treatment prior to the induction of the differentiation followed by a $24 \mathrm{~h}$ treatment at the onset of the differentiation. In this manner, we promoted the intracellular supply in NAC to ensure that its antioxidant effect happens during the initial differentiation phase. In contrast to AA treatment (Fig. 1b), the NAC treatment displayed an antioxidant effect as it limited the rise in the fluorescent signal occurring during the onset of differentiation when compared to control (Fig. 1c). Only a moderate increase of the signal was found at $1 \mathrm{~h}$ though significantly lower than for untreated cells; then the signal already returned to the baseline from $2 \mathrm{~h}$. Importantly, as seen for AA treatment (Fig. 1b) NAC did not significantly modify the redox balance in 24 h-treated proliferating cells (Fig. 1c; $t=0 \mathrm{~h}$ ) or after the cell fate commitment phase (Fig. 1c; $t=24 \mathrm{~h}$ ). Taken together, these data support the view that AA leads to a pro-oxidant effect when supplied to human NPCs in vitro.

To correlate the changes in redox balance with the reactive oxygen species (ROS) metabolism, we measured the overall ROS levels following AA treatment using DHR123 [40]. Changes in the DHR123 signal reflect changes in ROS levels as an enhanced signal resulted from treatment of proliferating cells with hydrogen peroxide $\left(\mathrm{H}_{2} \mathrm{O}_{2}\right)$ solution (Fig. 2a). The results obtained with the ROS sensor (Fig. 2b) recapitulated the data obtained through the use of the redox indicator. The fluorescent signal of DHR123 was significantly augmented upon $1 \mathrm{~h}$ of differentiation of untreated cells. Then it remained stable at $2 \mathrm{~h}$, returned to the baseline at $3 \mathrm{~h}$, and even decreased below the baseline at $24 \mathrm{~h}$ (Fig. 2b). AA treatment led to an earlier, higher and longer increase in ROS levels compared to untreated cells: the signal increased already from $0.5 \mathrm{~h}$ of differentiation, remained higher and stable up to $3 \mathrm{~h}$, and decreased only later (Fig. 2b). These data clearly demonstrate that AA induces a pro-oxidant effect in vitro during the onset of the differentiation of human NPCs. Additionally, we found that AA did not affect ROS levels either during proliferation (Fig. 2b; $t=0 \mathrm{~h}$ ) or after the cell fate commitment (Fig. 2b; $t=24 \mathrm{~h}$ ), as the levels at these periods were comparable with the ones from untreated cells. These findings corroborate the results obtained with the redox indicator. The fact that the redox balance and the ROS levels varied only during the first hours of

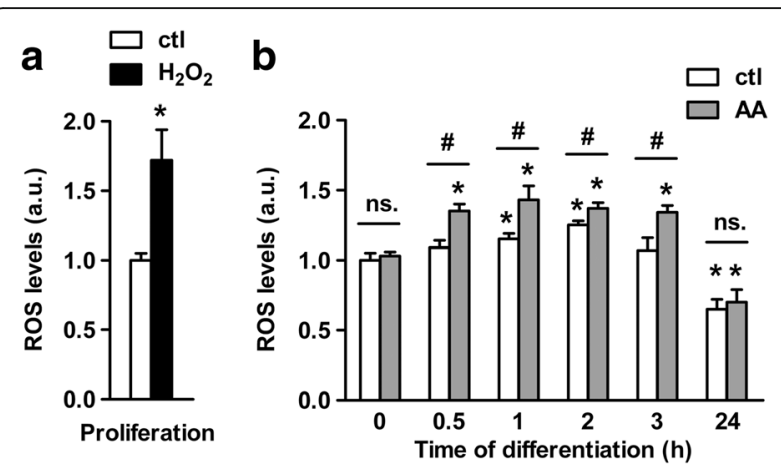

Fig. 2 AA treatment changes the intracellular ROS metabolism at the early stage of differentiation. a Intracellular ROS levels has been examined by flow cytometry in proliferating cells treated with $1 \mathrm{mM}$ $\mathrm{H}_{2} \mathrm{O}_{2}$ (positive control) for $1 \mathrm{~h}$. b ROS levels were also assessed along the first day of differentiation. Results were compared between untreated and AA-treated differentiating cells. $n=\sim 3.10^{4}$ cells per time point. Values are mean \pm SD of three independent experiments. ${ }^{*} P \leq 0.05$ compared with untreated differentiating cells at $\mathrm{t}=0 \mathrm{~h} ;{ }^{\#} P \leq 0.05$ between each treatment condition at each time point; ns, non-significant

the differentiation upon AA or NAC treatments infers that the molecular mechanisms facilitating the redox properties of these reagents take place strictly during this critical narrow period.

\section{Pro-oxidant effect of AA treatment during the cell fate commitment phase is involved in the increase in human NPCs neurogenesis}

As AA showed a pro-oxidant effect in vitro at the onset of human NPCs differentiation, we wondered whether such an effect could positively or negatively affect the neurogenesis output. We thus examined by confocal microscopy the cell population labelled with the specific neuronal marker Tubulin, Beta 3 Class III (TUBB3) [46] 3 days after the differentiation was induced (Fig. 3a). The neuronal yield was quantified by counting TUBB3-positive cells (Fig. 3b). Around 11\% of the untreated cell population differentiated into neurons after 3 days (Fig. 3a\&b) in accordance with previous report [26]. The differentiation process did not lead to any significant cell death as examined through the cell viability assay (Fig. 4a\&b). To demonstrate that cell response to early stimuli (i.e. during the onset of differentiation) drives the changes in the neuronal yield several days later, we treated the cells with lithium chloride $(\mathrm{LiCl}) . \mathrm{LiCl}$ is a potent glycogen synthase kinase 3 beta inhibitor [47], which has been previously reported to enhance $\mathrm{WNT} / \beta$-catenin-mediated neurogenesis from ReNcell VM cells, and so the neuronal yield [26]. Cells were treated with $\mathrm{LiCl} 1 \mathrm{~h}$ prior to the differentiation was initiated, followed by a 24 h-treatment from the induction of the differentiation. As anticipated $\mathrm{LiCl}$ 


\section{a}
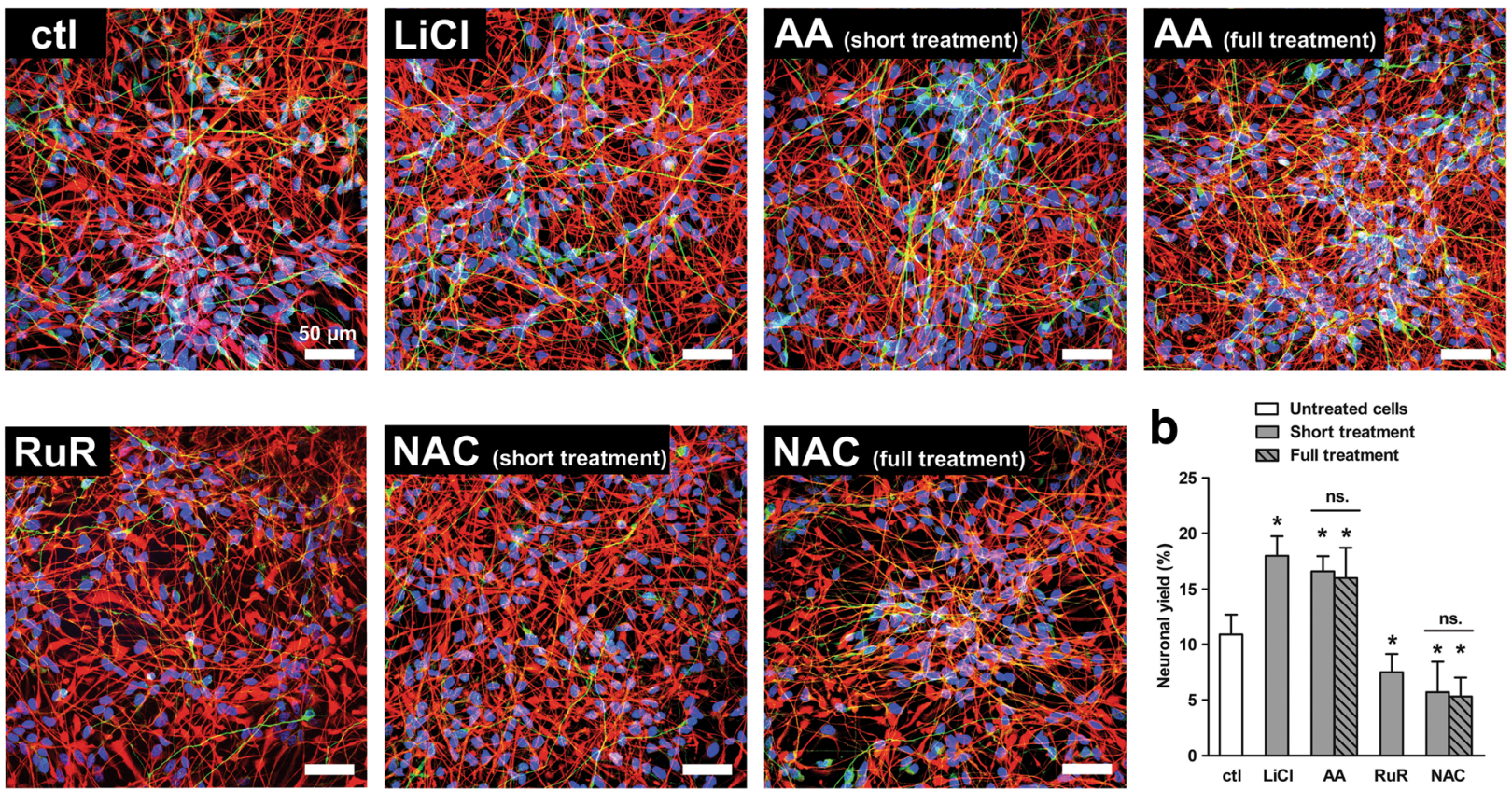

Fig. 3 AA treatment promotes human NPC neurogenesis. a Confocal images of neurons (TUBB3-positive cells: green) and glial cells (GFAP-positive cells: red) after $72 \mathrm{~h}$ of differentiation. The representative image panel in the figure was selected according to a comparable cell number for each condition ( $n=350$ to 400 cells per microscopic field). Scale: $50 \mu \mathrm{m}$. b Neurons were counted and the neuronal yield was then calculated (\% of the population). Data for untreated differentiated cells were compared with cells treated for two periods of incubation with $200 \mu \mathrm{M}$ AA or $5 \mathrm{mM} \mathrm{NAC} \mathrm{(short} \mathrm{treatment} \mathrm{vs.} \mathrm{full} \mathrm{treatment),} \mathrm{or} \mathrm{with} 15 \mathrm{mM} \mathrm{LiCl}$ or $0.5 \mu \mathrm{M}$ RuR. $n=\sim 3000$ cells per condition. Values are mean \pm SD of three independent experiments. ${ }^{*} P \leq 0.05$ compared with untreated differentiated cells at $t=72 \mathrm{~h} ;{ }^{*} P \leq 0.05$ between short treatment and full treatment for each condition; ns, non-significant

treatment enhanced the neuronal amount up to $70 \%$ after 3 days of differentiation (Fig. 3a\&b; 18\% of neurons). Moreover, no cytotoxicity was observed up to $24 \mathrm{~h}$ of differentiation i.e. during the cell fate commitment stage (Fig. 4a); the cell viability was however affected later though the reagent was not exposed to the cells anymore (Fig. 4a\&b; $25 \%$ and $\sim 30 \%$ of dead cells at $48 \mathrm{~h}$ and $72 \mathrm{~h}$, respectively). Next, we monitored neurogenesis ensuing the treatment of the cells with AA for $48 \mathrm{~h}$, i.e. $24 \mathrm{~h}$ prior to the differentiation was initiated and during the first $24 \mathrm{~h}$ at the onset of the differentiation. Then, the cells were deprived of AA for the following $48 \mathrm{~h}$ (Fig. 3a; see AA short treatment). We found that such treatment led to a pro-neurogenic effect as effective as $\mathrm{LiCl}$ (Fig. 3a\&b; 16\% vs. 18\% of neurons, respectively) and in a non-lethal manner (Fig. 4a\&b; AA short treatment). Moreover, AA pre-treatment of the proliferating cells for $24 \mathrm{~h}$ did not affect the cell number that remained comparable with untreated proliferating cells (Fig. 4b). We then extended the treatment period with AA up to the third day of differentiation, i.e. $96 \mathrm{~h}$-treatment in total (Fig. 3a; see AA full treatment). Interestingly, the full treatment resulted in a neuronal yield similar to the one obtained during the short treatment (Fig. 3b; 16\% of neurons for both short and full treatments), and yet without inducing any cytotoxicity (Fig. 4b). Hence, AA enhances the neuronal yield without displaying any effects on the cell viability, and the pro-neurogenic mechanisms of AA happen only during the early period of the differentiation process.

We also quantified the neuronal yield resulting from cell treatment with compounds displaying antioxidant effects. First, we used ruthenium red (RuR); as we previously reported it reduces the $\mathrm{Ca}^{2+}$-mediated ROS metabolism i.e. ROS levels, by reversibly inhibiting the mitochondrial calcium uniporter [26]. Since a full treatment with RuR is highly cytotoxic (Fig. 4b; 95\% of dead cells), we performed a short treatment at the onset of differentiation (i.e. 3 h-treatment in total) which did not affect the cell viability as measured daily up to the third day of differentiation (Fig. 4a\&b). RuR treatment reduced the neuronal amount (Fig. 3a) by 30\% (Fig. 3b; 7\% of neurons). Second, cells were treated with NAC only in the same way than AA: $24 \mathrm{~h}$-pre-treatment followed by either a $24 \mathrm{~h}$ - or $72 \mathrm{~h}$-treatment upon the differentiation. Importantly, both short and full treatments with NAC similarly inhibited the neurogenesis (Fig. 3a\&b; $\sim 6 \%$ of neurons at $72 \mathrm{~h}$ ). NAC treatment did not induce 


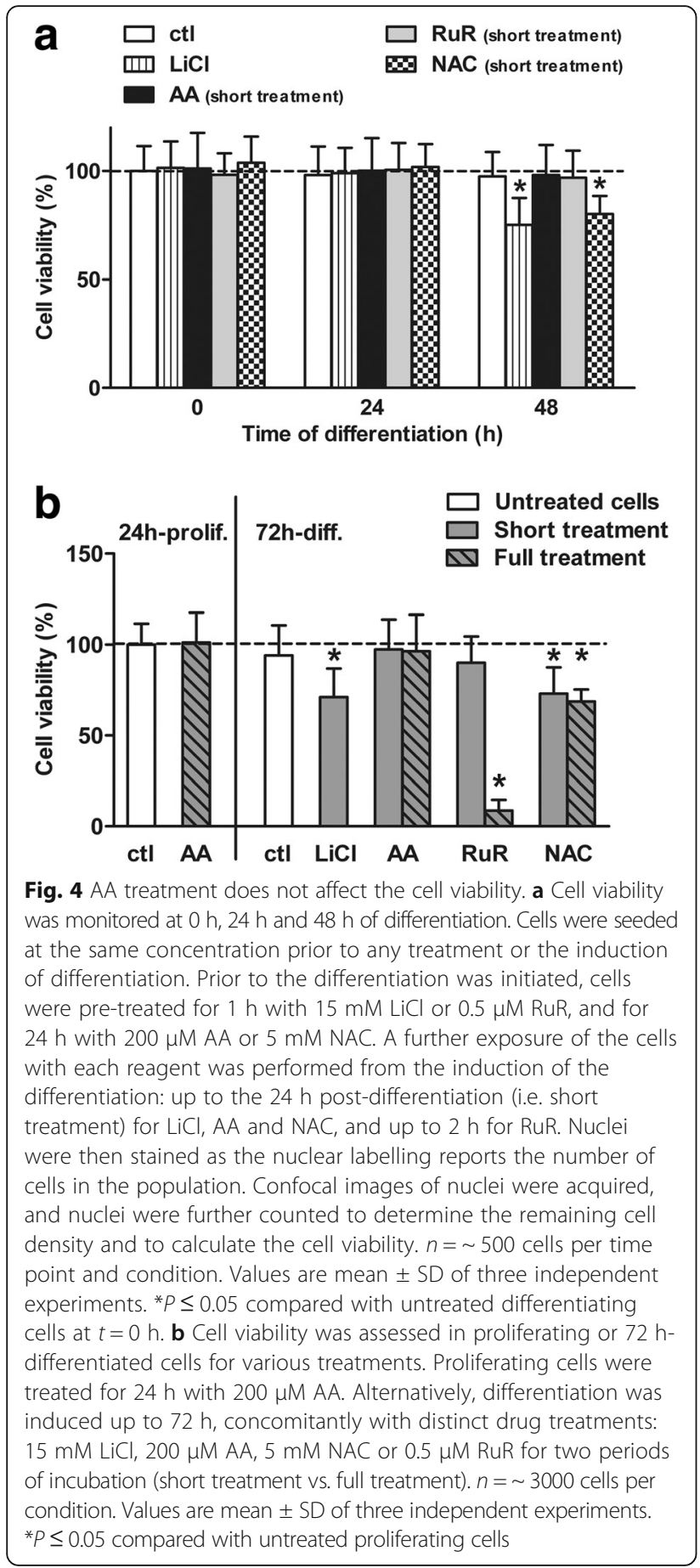

any cytotoxic effect during the cell fate commitment phase (Fig. 4a; see at $24 \mathrm{~h}$ ); yet both treatment periods led to a comparable extent in cell death later (Fig. 4a\&b; $\sim 30 \%$ of dead cells at $72 \mathrm{~h}$ ). These results imply that extending NAC treatment beyond the cell fate commitment period does not have any supplemental inhibitory effect on neurogenesis. Furthermore, both RuR and NAC display a reverse pattern to AA: they exert antioxidant activities (see here Fig. 1b, and [26]) and they negatively modulate the neurogenesis. Therefore, the data stress the pivotal role of redox events at the early phase of differentiation in the neuronal output of human NPCs.

To substantiate the findings obtained by microscopy, we further examined by quantitative real-time PCR the responsiveness of the neuronal marker TUBB3 gene in a shorter differentiation time scale i.e. at $24 \mathrm{~h}$ and $48 \mathrm{~h}$ of differentiation (Fig. 5). All treatments did not exceed the first day of differentiation to ensure that any changes in the neuronal output are connected to perturbations during the neuronal fate commitment stage only. Once the differentiation was induced by withdrawing growth factors, TUBB3 mRNA level was up-regulated at $48 \mathrm{~h}$ (Fig. 5; 2.0-fold increase for control) confirming that cells undergo neuronal differentiation. As positive control, 24 h-exposure of the cells to the pro-neurogenic factor $\mathrm{LiCl}$ [26] already enhanced TUBB3 mRNA level from $24 \mathrm{~h}$ (Fig. 5; 2.0-fold increase) to reach a 3.5 -fold increase at $48 \mathrm{~h}$. In line with the microscopy data, the short treatment with AA up-regulated TUBB3 gene response in a comparable manner with $\mathrm{LiCl}$ : the mRNA level steadily increased by 1.7 -fold already at $24 \mathrm{~h}$ and by 3-fold at $48 \mathrm{~h}$ (Fig. 5). Conversely, 3 h-treatment of the cells with the ROS metabolism inhibitor RuR at the onset of the differentiation prevented the rise in TUBB3 mRNA level by half at $48 \mathrm{~h}$ when compared with untreated cells (Fig. 5; 1.5-fold vs. 2.0-fold increase, respectively). Therefore, our data support that the pro-

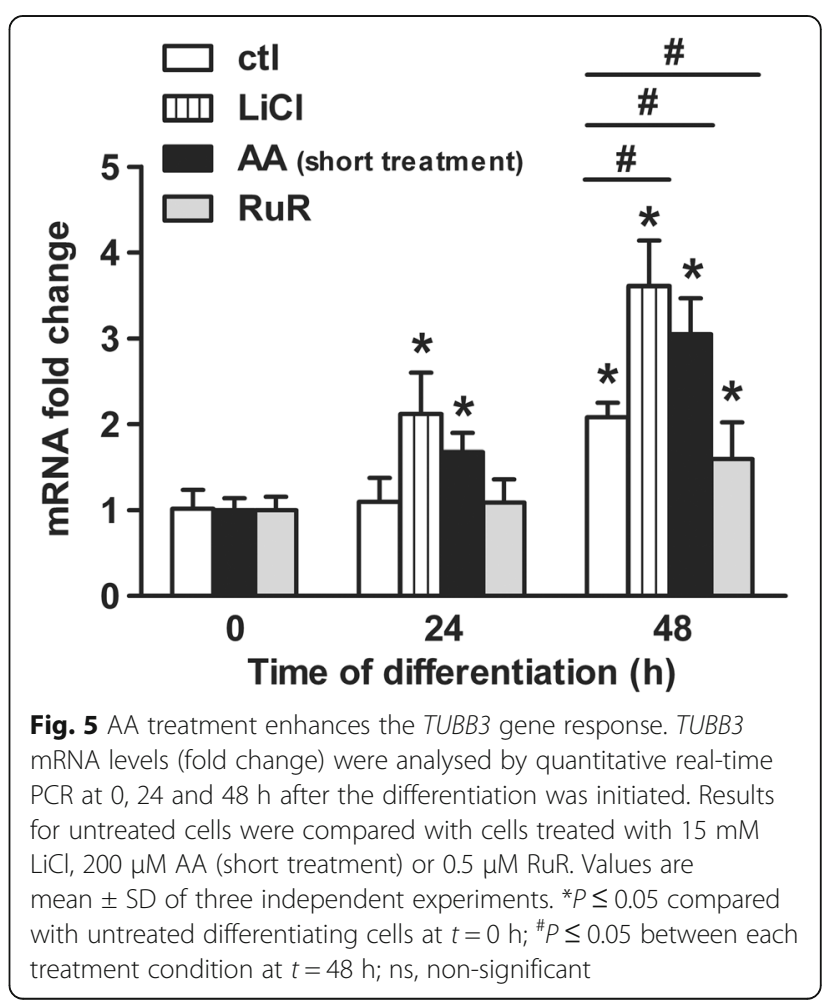


oxidant effect of AA is instrumental during the cell fate commitment phase for improving the neuronal differentiation of human NPCs.

\section{AA treatment stimulates the WNT/ $\beta$-catenin signal transduction and the redox-sensitive DVL2-NXN complex dissociation during the cell fate commitment phase} The neuronal commitment of human NPCs depends on the $\mathrm{WNT} / \beta$-catenin signaling output that can be regulated from the first hours of differentiation by redoxsensitive events [26]. We therefore wondered whether AA pro-oxidant effect at the onset of the differentiation may alter the response of $\mathrm{WNT} / \beta$-catenin pathway target genes. We then assessed the expression level of $\mathrm{v}$ myc avian myelocytomatosis viral oncogene homolog $(M Y C)$ gene [48]. Since $M Y C$ expression has been reported to regulate the neuronal differentiation process of ReNcell VM cells [36], its expression level reflects both the neurogenesis and the $\mathrm{WNT} / \beta$-catenin pathway outputs. Consistent with previous report [36], we found an up-regulation of $M Y C$ mRNA level $48 \mathrm{~h}$ after the differentiation was induced in untreated cells (Fig. 6; 2.5-fold increase). Moreover, incubating the cells along the first day of differentiation with the $\mathrm{WNT} / \beta$-catenin pathway stimulator LiCl [47] predictably enhanced $M Y C$ gene response to high levels at both $24 \mathrm{~h}$ and $48 \mathrm{~h}$ postdifferentiation (Fig. 6; 10-fold and 15-fold increases,

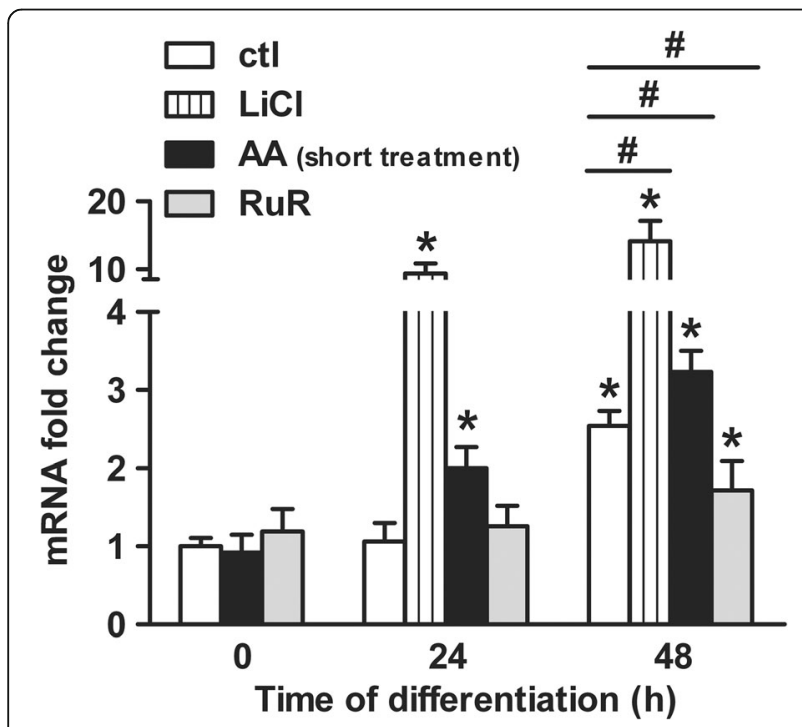

Fig. 6 AA treatment stimulates the expression of the WNT/ $\beta$-catenin signaling target gene MYC. MYC mRNA levels (fold change) were evaluated by quantitative real-time PCR at 0,24 and $48 \mathrm{~h}$ after the differentiation was induced. Data for untreated cells were compared with cells treated with $15 \mathrm{mM} \mathrm{LiCl}, 200 \mu \mathrm{M}$ AA (short treatment) or $0.5 \mu \mathrm{M}$ RuR. Values are mean \pm SD of three independent experiments. ${ }^{*} P \leq 0.05$ compared with untreated differentiating cells at $t=0 \mathrm{~h} ;{ }^{\sharp} P \leq$ 0.05 between each treatment condition at $t=48 \mathrm{~h}$; ns, non-significant respectively). Importantly, exposure of the cells to AA up to the first day of differentiation (i.e. short treatment) also led to an up-regulation of $M Y C$ gene expression. A significant increase of the mRNA level up to 2-fold was found at $24 \mathrm{~h}$ and to 3 -fold at $48 \mathrm{~h}$ (Fig. 6). In contrast, treatment with RuR limited the rise in $M Y C$ gene response as the mRNA level increased only to 1.7 -fold at $48 \mathrm{~h}$ (Fig. 6). Altogether, these findings support the idea that the pro-neurogenic effect of AA is connected to both the pro-oxidant effect of the reagent during the neuronal fate commitment phase and the stimulation of early redox-dependent events altering $\mathrm{WNT} / \beta$-catenin signaling response.

Nucleoredoxin (NXN) is an endogenous antioxidant [38] sequestering the $\mathrm{WNT} / \beta$-catenin signaling key component Dishevelled segment polarity protein 2 (DVL2) [37, 39]. The release of the initial pool of DVL2 at the early stage of the differentiation is a redoxsensitive step required for relaying the WNT signal to downstream effectors [26]. Accordingly, we examined whether the early changes in ROS metabolism resulting from AA treatment may impact on DVL2 release from NXN. DVL2-NXN complex dissociation was measured by fluorescence resonance energy transfer (FRET) microscopy (Fig. 7a), and FRET efficiencies $\left(\right.$ FRET $\left._{\text {eff }}\right)$ were quantified in proliferating cells and during the first $4 \mathrm{~h}$ of differentiation (Fig. $7 \mathrm{~b} \& \mathrm{c}$ ). To confirm that changes in $\mathrm{FRET}_{\text {eff }}$ solely depend in ROS levels, we treated proliferating cells for $1 \mathrm{~h}$ with $1 \mathrm{mM} \mathrm{H}_{2} \mathrm{O}_{2}$ to enhance the intracellular ROS concentration. FRET eff $_{\text {strongly de- }}$ creased to 10-fold compared to untreated proliferating cells (Fig. 7a\&b; ctl vs. $\mathrm{H}_{2} \mathrm{O}_{2}$ ), indicating a DVL2-NXN complex dissociation. Furthermore, we substantiated that $\mathrm{FRET}_{\text {eff }}$ reduction did not result from any diminishing protein quantities since both DVL2 and NXN amounts increased after $\mathrm{H}_{2} \mathrm{O}_{2}$ treatment as quantified by fluorescence imaging (Additional file 1: Figure S1). We then monitored FRET $_{\text {eff }}$ during the first hours of differentiation of untreated cells. FRET eff $_{\text {significantly }}$ diminished by 1.9 -fold at $1 \mathrm{~h}$ of differentiation and by 5 -fold at $2 \mathrm{~h}$ (Fig. 7a\&c). After $2 \mathrm{~h}, \mathrm{FRET}_{\text {eff }}$ values remained low (Fig. 7a\&c; 10-fold decrease at $3 \mathrm{~h}$ and $4 \mathrm{~h})$. Although variations of both DVL2 and NXN amounts were held during this narrow time range (Additional file 1: Figure S1), they are not correlated with the changes in $\mathrm{FRET}_{\text {eff, }}$, and so they did not inter-

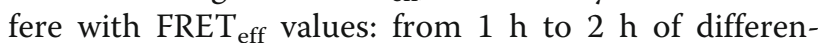
tiation both proteins showed elevated levels while FRET $_{\text {eff }}$ values decreased; the next $2 \mathrm{~h}$ the protein amounts returned to baseline while FRET $_{\text {eff }}$ remained unchanged. In accordance with our previous study [26], the reduction in $\mathrm{FRET}_{\text {eff }}$ values is instead temporally correlated with the rise in ROS metabolism observed at the early stage of differentiation (see Fig. 2b): FRET $_{\text {eff }}$ 


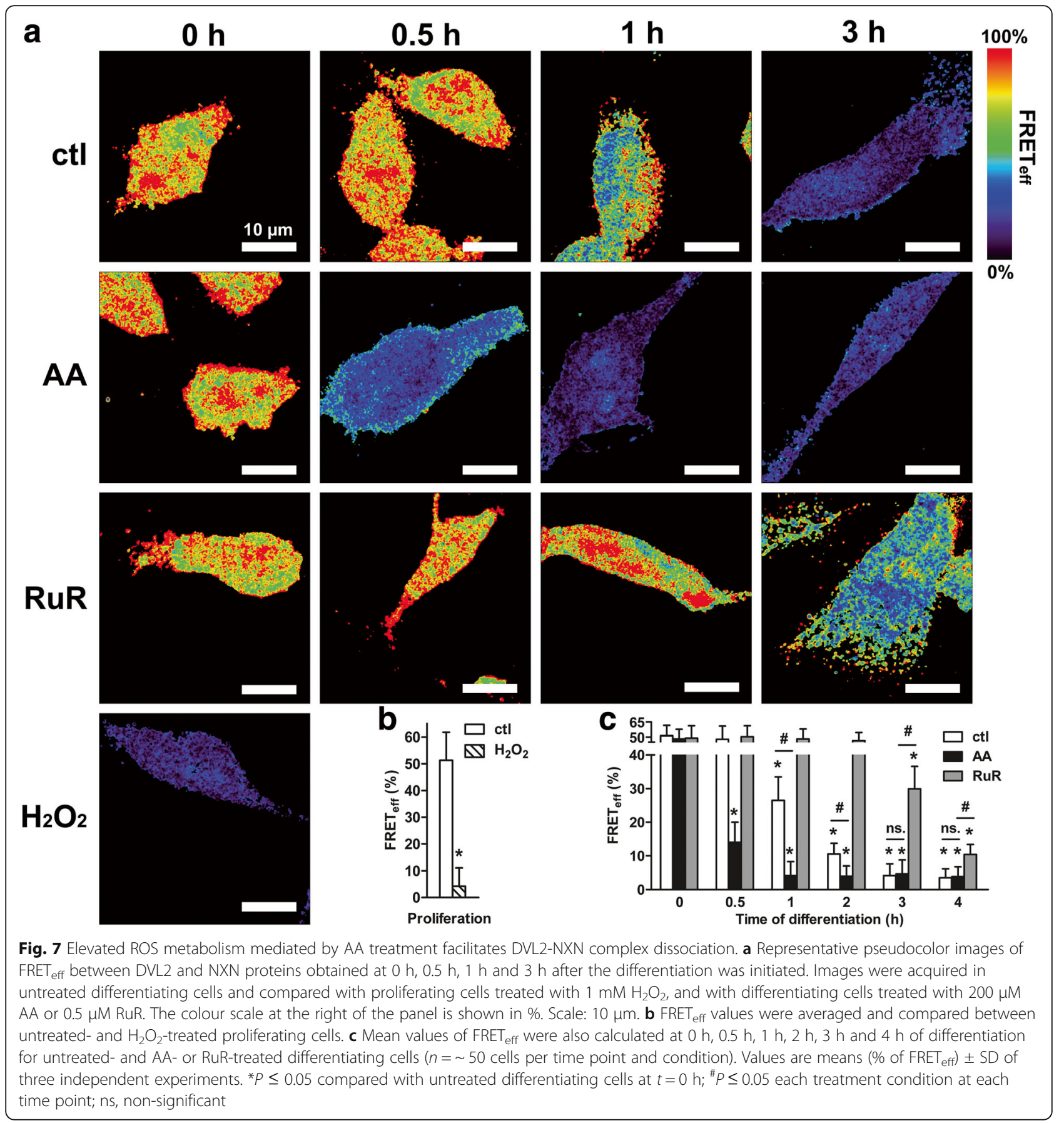

started to decrease at $1 \mathrm{~h}$ when ROS levels significantly increased, and the strongest reduction of the $\mathrm{FRET}_{\text {eff }}$ value happened at $3 \mathrm{~h}$ when the highest levels of ROS were reached and maintained in a plateau. Though ROS levels returned at baseline at $4 \mathrm{~h}, \mathrm{FRET}_{\text {eff }}$ still remained at its lowest value indicating that both proteins do not reassociate anymore; the cells do no longer maintain high ROS metabolism for promoting DVL2 release as the protein complexes were already fully dissociated [26].
Next, we examined whether AA treatment alters the redox-sensitive DVL2-NXN dissociation. Strikingly, we found that changes in $\mathrm{FRET}_{\text {eff }}$ correlates with the variations in ROS metabolism mediated by the treatment. Neither ROS levels (see Fig. 2b) nor FRET eff $_{\text {varied in }}$ spite of the $24 \mathrm{~h}$-pre-treatment with AA prior to the induction of differentiation (Fig. 7a\&c; $t=0 \mathrm{~h}$, ctl vs. AA). However, $_{\text {FRET }}$ eff decreased by 3.3 fold from $0.5 \mathrm{~h}$ of differentiation i.e. simultaneously with the beginning of the rise in ROS metabolism resulting from AA treatment; a 
maximum $\mathrm{FRET}_{\text {eff }}$ reduction by $\sim 10$ fold was already reached at $1 \mathrm{~h}$ (Fig. 7a\&c). Here again, the FRET ${ }_{\text {eff }}$ reduction did not result from any diminution in the protein amounts as they rather increased at $0.5 \mathrm{~h}$ (Additional file 1: Figure S1). Therefore, AA treatment accelerated the DVL2-NXN complex dissociation just as it did for ROS production. Conversely, inhibiting ROS metabolism prevented the complex dissociation as shown in RuR-treated cells (Fig. 7a\&c; ctl vs. RuR). FRET $_{\text {eff }}$ remained unaltered up to $2 \mathrm{~h}$ of differentiation; it started to decrease only from $3 \mathrm{~h}$ (Fig. 7a\&c; 1.6 foldreduction) i.e. when RuR antioxidant effect was alleviated since we stopped the cell exposure to the drug [26]. As the protein quantities augmented at $3 \mathrm{~h}$ instead of being diminished (Additional file 1: Figure S1), it is unlikely that protein amounts interfered with $\mathrm{FRET}_{\text {eff }}$

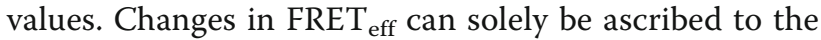
variations in ROS metabolism mediated by each treatment. Accordingly, these data corroborate that the release of DVL2 from its complex with NXN is positively regulated by ROS levels. Moreover, they show that the elevated ROS metabolism mediated by AA treatment prior to the cell fate decision facilitates the release of the initial protein pool of the $\mathrm{WNT} / \beta$-catenin signaling mediator DVL2.

\section{Discussion}

In this study, we aimed to unravel whether and how AA redox property is involved in the well recognized proneurogenic effect of the reagent when supplemented at physiological doses to NPCs. Consistent with previous reports from mouse and rat progenitors [7-17], we show here that treating differentiating human NPCs (i.e. ReNcell VM cells) with AA at a physiological dose [6] stimulates their neurogenesis in vitro (Fig. 3 and 5). Yet evidence of AA effect on redox state during neuronal differentiation of NPCs have been lacking so far [7-18]. Our study provides direct measures of intracellular ROS levels (Fig. 1 and 2) and reveals that the positive regulation of the neurogenesis of human NPCs by AA is accompanied by a pro-oxidant effect mediated by the reagent during the cell fate commitment phase. Although our findings contrast with the in vivo AA antioxidant activity, one has to emphasize that many investigations support a prooxidant effect ex vivo $[27,28]$ and in vitro [29-32]. Furthermore, a few studies performed in cultured rodent progenitor cells corroborate that AA acts as pro-oxidant. First, Yu DH, et al., [15] showed that AA-mediated dopaminergic differentiation of rat mesencephalic precursors is accompanied with an up-regulation of gene products that protect against oxidative damages. Although no direct assessment of ROS levels has been performed, the authors attributed the rise in the antioxidant defense to a cellular response to AA pro-oxidant properties. Second, Bartsch C, et al., [49] reported that AA treatment of mouse embryonic stem cells increases ROS levels and stimulates the cardiomyogenesis.

Furthermore, we report that the positive regulation of the neuronal differentiation of human NPCs by AA is independent of any effects on cell viability. The effect of AA treatment on NPCs neurogenesis and viability was compared to the treatments with the proneurogenic reagent $\mathrm{LiCl}$ [26] and the antioxidant NAC [45]. Several studies emphasized the therapeutical potential of $\mathrm{LiCl}$ in cell replacement therapies for CNS regeneration [50-52]. Our data corroborate these previous reports; $\mathrm{LiCl}$ enhances neurogenesis in our cell model as shown by the increases of both the expression of the neuronal marker TUBB3 gene from $24 \mathrm{~h}$ (Fig. 5) and the neuronal amount quantified at $72 \mathrm{~h}$ by microscopy (Fig. 3). $\mathrm{LiCl}$ treatment did not display any cytotoxic effect during the cell fate commitment period i.e. the first $24 \mathrm{~h}$; yet it led to cell death later (Fig. 4). Of note, $\mathrm{LiCl}$ cytotoxicity has been reported for comparable dose ranges and exposition times of the drug in various cell types [53, 54]. Moreover, it is unlikely that the increased quantity of neurons measured at 3 days following the treatment mainly resulted from a toxicity affecting selectively the nonneuronal cells; it has been reported that cytotoxic doses of $\mathrm{LiCl}$ impaired without distinction both neuronal and glial cell subpopulations differentiated from rat neural progenitors [50]. As for NAC, it led to a late cytotoxicity comparable with $\mathrm{LiCl}$ although the antioxidant induced an opposite effect on neurogenesis. Such a cytotoxic effect of the reagent is known for long-term treatments with millimolar doses [55-57]. Conversely, AA enhances the neuronal yield as much as $\mathrm{LiCl}$ but in a non-lethal manner, though these findings contrast with studies reporting that AA promotes cytotoxicity in vitro $[27,28,58]$. Given that AA treatment increases ROS metabolism, one could have anticipated a rise in cell damage and death resulting from an excessive ROS production [33]. However, whatever the exposure duration (short- vs. long treatment) the physiological dose of $200 \mu \mathrm{M}$ of AA is not cytotoxic in our study, making it unlikely that AA mediated a ROS generation sufficient to induce an oxidative stress. One could then wonder whether the non-lethal moderate increase in the intracellular production of ROS mediated by AA treatment may rather act as messengers regulating redoxdependent events [25] which positively influence human NPCs neurogenesis.

Our earlier investigations in ReNcell VM cells revealed that the first hours of differentiation are crucial in the regulation of the neuronal output as this early period happens prior to the neuronal fate commitment $[26,35]$. In addition, we previously demonstrated that changes in ROS metabolic cues are endogenously induced during a 
tight timing occurring right from the first hours upon the initiation of neuronal differentiation of the cells $[26,35]$. The physiologic switch in ROS metabolism was found to modulate the response amplitude of the $\mathrm{WNT} / \beta$-catenin pathway via the control of the activity of the redox-sensitive target $\mathrm{NXN}$, an ubiquitous antioxidant [38] that sequestrates the $\mathrm{WNT} / \beta$-catenin signaling downstream effector DVL2 [26]. In ReNcell VM cells the WNT/ $\beta$-catenin pathway has been found to regulate the neuronal differentiation [36], and the early modulation of this pathway by ROS has been shown to further alter the neuronal commitment of the cells [26]. Remarkably, our current data unravel that AA pro-oxidant effect strictly takes place during the first hours of differentiation. Moreover, it has been reported that AA treatment down-regulates the expression of the glycogen synthase kinase 3 beta gene during neuronal differentiation of rat precursors [15] suggesting that AA may influence $\mathrm{WNT} / \beta$-catenin pathway output. Taking all of these observations together, we reasoned that both AA pro-neurogenic and pro-oxidant effects may be connected together through the stimulation of the redox-sensitive WNT/ $\beta$-catenin pathway, which subsequently could alter the neuronal differentiation of human NPCs. Our current findings show that the inhibition of ROS metabolism by antioxidants reduces both the $\mathrm{WNT} / \beta$-catenin signaling output i.e. $M Y C$ gene expression (Fig. 6) and the neurogenesis (Fig. 3 and 5). Conversely, AA enhances the $\mathrm{WNT} / \beta$-catenin signaling response and the neuronal yield. Importantly, one has to point out that changes in the magnitudes of both the $\mathrm{WNT} / \beta$-catenin signaling response and the neurogenesis are solely linked to the alterations of the ROS metabolism prior to the neuronal fate commitment. First, beyond the cell fate commitment phase (i.e. at 24-h post-differentiation), neither NAC nor AA treatments affect the intracellular ROS metabolism as the levels are similar to untreated differentiated cells. Second, full treatments (i.e. up to 72-h post-differentiation) with either NAC or AA modify the neuronal yields similarly to short treatments (i.e. up to 24$\mathrm{h}$ post-differentiation).

By which mechanism the ROS production mediated by AA treatment may interfere with the $\mathrm{WNT} / \beta$-catenin pathway and so the neurogenesis? Interestingly, our data indicate that the variations in the $\mathrm{WNT} / \beta$-catenin signaling outputs are related to the extent in the ROSdependent dissociation of DVL2-NXN complexes at the beginning of the differentiation process. We previously reported that during the proliferation of human NPCs an initial pool of DVL2 is kept inactive as the proteins bind to NXN molecules [26]. Once ROS metabolism increases at the onset of the differentiation, DVL2 proteins dissociate from NXN, and thus are activated and recruited in the signaling cascade for relaying downstream the signal [26]. In line with this previous report, we corroborate by FRET microscopy that the protein complex dissociation is temporally correlated to ROS metabolism at the onset of the human NPCs differentiation (compare Fig. 2 vs Fig. 7). In addition, we demonstrate that the extent of DVL2 release is regulated by the amplitude and the promptness of the ROS production: a delayed and low DVL2 dissociation resulted from the inhibition of mitochondrial ROS formation mediated by the early and punctual RuR treatment (Fig. 7 and [26]); in contrast, a strong DVL2 release followed the treatment of proliferating cells with the pro-oxidant reagent $\mathrm{H}_{2} \mathrm{O}_{2}$ (Fig. 7 and [37]). As for AA, we reveal that the initial inactive pool of sequestered DVL2 promptly dissociates as a result of the early and high increase in ROS metabolism following the treatment. The dissociation of the totality of the protein complexes happens quickly in response to the maintaining of high ROS levels. Next, the proteins do not form complexes anymore despite their intracellular accumulation and further de novo synthesis (Additional file 1: Figure S1 and [26]); NXN are rather implicated in detoxifying ROS. No protein reassociation occurs even after the ROS metabolism returned to baseline. Once released, DVL2 proteins become active and commit to the $\mathrm{WNT} / \beta$-catenin signaling cascade [26]. DVL2 release tunes the extent of the WNT/ $\beta$-catenin signal transduction; in other words, the earlier the initial pool of DVL2 is released and activated during the cell fate commitment stage, the more efficient and sustained is the signal [26]. Accordingly, the elevated ROS metabolism mediated by AA treatment prior to the cell fate decision facilitates DVL2 activation, and so ameliorates the efficiency of the $\mathrm{WNT} / \beta$-catenin signal transduction; this leads to an enhanced expression of target genes e.g. MYC and TUBB3 [36], that finally results in an augmented neuronal yield.

The molecular mechanisms by which AA increases intracellular ROS formation in our in vitro human NPCs model have not been thoroughly investigated here. In this study, we focused on the concentration of $200 \mu \mathrm{M}$ since this physiological dose has been mostly used in the reports emphasizing a positive role of AA in NPCs neurogenesis; one should therefore cautiously consider that the mechanisms implicated in AA-mediated ROS depend on the dose of the compound. One could however suggest a mechanism involving redox reactions resulting from AA conversion to substrates. It has been reported that AA pro-oxidant effect results from its extracellular oxidation to dehydroascorbate that is transported in the cells and further reduced back to ascorbate [59]. However, since these reactions also lead to cell death $[27,28]$ such a mechanism may be unlikely in ReNcell VM cells, as AA did not alter their viability. 
Another conceivable mechanism may implicate AA interaction with transition metal ions although conflicting studies are reported. First, such interactions either increase [31, 32] or decrease the ROS production [20]. Next, both pro- and antioxidant effects happen simultaneously but in distinct compartments, i.e. respectively in intracellular and extracellular compartments [29]. Finally, AA-mediated ROS production is found independent from any interactions with transition metal ions $[27,28]$. Thus, further studies are needed to elucidate how physiological doses of AA mediate ROS generation in our cells. As this was observed only during the cell fate commitment period, one could suggest that the molecular machinery required for this process may depend on the cellular differentiation and metabolic stage of the NPCs. Such molecular machinery may be efficient in cells at the early stage of differentiation, but neither during the proliferation stage nor in partially or terminally differentiated cells.

To date, besides the pro-oxidant effect of AA treatment demonstrated in this study, a few more potential mechanisms have been previously proposed to explain AA pro-neurogenic effects. Considering findings indicating that AA protects cells from apoptosis [60] and that dopamine auto-oxidation causes neuronal damages [58], one could speculate that AA antioxidant property might protect neurons from dopamine-mediated cytotoxic effect. Such a hypothesis is however questionable. First, many investigations challenge AA antioxidant properties [27-32]. Second, AA is also reported either potentiating the dopamine-mediated neurotoxicity [58] or failing to expand dopaminergic differentiation at doses preventing a potential dopamine auto-oxidation [9]. A more likely additional mechanism that can be attributed to AA treatment involves the stimulation of the extracellular matrix assembly needed for the development of nervous system [61]. Such mechanism is consistent with findings from Shin DM, et al., [13] showing that AA treatment up-regulates the expression of genes encoding for the extracellular membraneassociated protein pleiotrophin and the extracellular matrix glycoprotein vitronectin during the neuronal differentiation of mouse precursors. Furthermore, $\mathrm{Yu}$ $\mathrm{DH}$, et al., [15] report an up-regulation of the expression levels of procollagen genes in neurons differentiated from cultured rat precursors treated with AA. Therefore, we do not exclude that AA pro-neurogenic effect in human NPCs can rely on other activities of the reagent in addition to its pro-oxidant effect. Actually, it is likely that both AA mechanisms i.e. ROS-mediated signaling and extracellular matrix remodeling, can act in concert to positively modulate NPCs neurogenesis as it is well-accepted that extracellular matrix interacts with signaling pathways [62].

\section{Conclusions}

Our study reveals that the beneficial role of AA treatment in the neuronal differentiation of human NPCs results from its non-lethal pro-oxidant effect. Moreover, our findings are consistent with studies performed in rodent precursors showing that AA stimulates expression of genes involved in neuronal development and maturation, as well as gene responsiveness for products implicated in signaling pathways that control the neuronal cell fate determination $[13,15]$. Here, we demonstrate in human NPCs that increased ROS metabolic cues following AA treatment are strictly anchored to a period prior to the neuronal fate commitment. Such elevated ROS metabolism promotes DVL2 activation by facilitating the dissociation of the initial inactivated pool of the proteins from NXN sequestration. As a result, the $\mathrm{WNT} / \beta$-catenin signal transduction is ameliorated and enhances neurogenic gene expression that stimulates the decision of the cells to commit to their neuronal fate. Our findings also point out the substantial role of the redox balance in in vitro cultured NPCs for improving the neuronal yield necessary for transplantation in regenerative therapies. Finally, they emphasize the importance to control carefully the experimental conditions including the compounds in the cell culture media as previously suggested [63].

\section{Additional files}

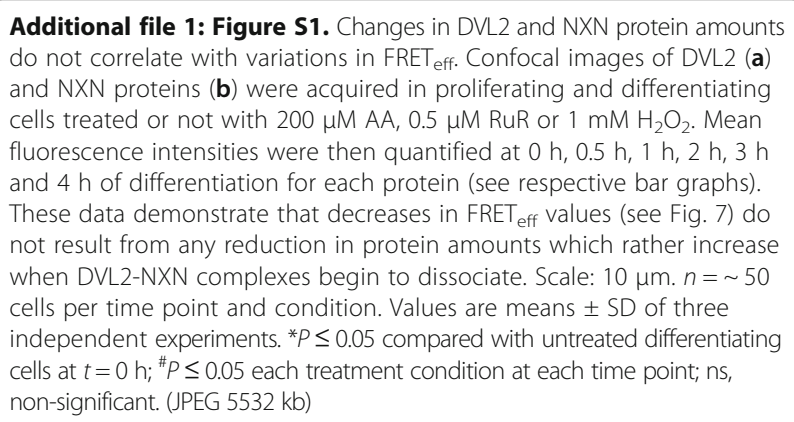

\section{Abbreviations}

AA: Ascorbic acid; Carboxy-H2DCFDA: 5(6)-carboxy-2',7'

dichlorodihydrofluorescein diacetate; CNS: Central nervous system;

DHR123: Dihydrorhodamine 123; DVL2: Dishevelled segment polarity protein

2; FRET $_{\text {eff: }}$ Fluorescence resonance energy transfer efficiency; GFAP: Glial

fibrillary acidic protein; $\mathrm{H}_{2} \mathrm{O}_{2}$ : Hydrogen peroxide; LiCl: Lithium chloride;

MYC: v-myc avian myelocytomatosis viral oncogene homolog; NAC: N-acetyl-

L-cysteine; NPCs: Neural progenitor cells; NXN: Nucleoredoxin; PMA: Phorbol

12-myristate 13-acetate; ROS: Reactive oxygen species; RPL13A: Ribosomal

protein L13a; RuR: Ruthenium red; TUBB3: Tubulin, beta 3 class III

\section{Acknowledgements}

The authors are grateful to Bärbel Redlich-Witt and Birgit Wobith from the University of Rostock, Germany, for excellent technical assistance.

\section{Funding}

This work was supported by the Helmholtz Association Young Investigator Groups program to DP, and by the German Research Foundation (DFG) as 
part of the Research Training Group GRK 1387/1 dIEM oSiRiS (Rostock, Germany) to DGW.

\section{Availability of data and materials}

All data generated or analysed during this study are included in this published article and its supplementary information file.

\section{Authors' contributions}

TR designed the study, performed cell culture, confocal microscopy, FRET and $\mathrm{QPCR}$ experiments, analysed the data, and wrote the manuscript. ML performed flow cytometry experiments. AG carried on cell viability assay. DGW, DP and SL provided research facilities, and contributed to the design of the study and the interpretation of the data. DP and SL assisted in the preparation of the manuscript draft and supervised the study. All authors read, critically reviewed, and approved the final manuscript.

\section{Ethics approval and consent to participate}

Not applicable.

\section{Consent for publication}

Not applicable.

\section{Competing interests}

The authors declare that they have no competing interests.

\section{Publisher's Note}

Springer Nature remains neutral with regard to jurisdictional claims in published maps and institutional affiliations.

\section{Author details}

${ }^{1}$ Physiopathology of Inflammatory Bone Diseases, University of the Littoral Opal Coast, F-62327 Boulogne sur Mer, France. ${ }^{2}$ Electrochemical Signaling in Development and Disease, Max Delbrück Center for Molecular Medicine in the Helmholtz Association, D-13125 Berlin, Germany. ${ }^{3}$ Cell Biology and Biosystems Technology, Institute of Biological Sciences, University of Rostock, D-18059 Rostock, Germany. ${ }^{4}$ Department of Animal Physiology, Faculty of Sciences and Technics, University of Abomey-Calavi, 01BP 526 Cotonou, Benin. ${ }^{5}$ DZHK (German Centre for Cardiovascular Research), Partner Site Berlin, D-13125 Berlin, Germany. ${ }^{6}$ Physiopathology of Inflammatory Bone Diseases, University of the Littoral Opal Coast, Boulevard Bassin Napoléon Quai Masset, B.P. 120, F-62327 Boulogne sur Mer, Cédex, France.

Received: 24 June 2017 Accepted: 6 October 2017

\section{Published online: 16 October 2017}

\section{References}

1. Abdel-Salam OM. Stem cell therapy for Alzheimer's disease. CNS Neurol Disord-DR. 2011;10(4):459-85.

2. Maucksch C, Vazey EM, Gordon RJ, Connor B. Stem cell-based therapy for Huntington's disease. J Cell Biochem. 2013;114(4):754-63.

3. Lindvall O, Kokaia Z, Martinez-Serrano A. Stem cell therapy for human neurodegenerative disorders-how to make it work. Nature Med. 2004;10(Suppl):S42-50

4. Studer L, Tabar V, McKay RDG. Transplantation of expanded mesencephalic precursors leads to recovery in parkinsonian rats. Nature Neurosci. 1998;1(4):290-5.

5. Sánchez-Pernaute R, Studer L, Bankiewicz KS, Major EO, McKay RDG. In vitro generation and transplantation of precursor-derived human dopamine neurons. J Neurosci Res. 2001;65(4):284-8.

6. Miele M, Fillenz M. In vivo determination of extracellular brain ascorbate. J Neurosci Meth. 1996;70(1):15-9.

7. Kalir HH, Mytilineou C. Ascorbic acid in mesencephalic cultures: effects on dopaminergic neuron development. J Neurochem. 1991;57(2):458-64.

8. Lee SH, Lumelsky N, Studer L, Auerbach JM, McKay RD. Efficient generation of midbrain and hindbrain neurons from mouse embryonic stem cells. Nature Biotechnol. 2000;18(6):675-9.

9. Yan J, Studer L, McKay RDG. Ascorbic acid increases the yield of dopaminergic neurons derived from basic fibroblast growth factor expanded mesencephalic precursors. J Neurochem. 2001;76(1):307-11.

10. Chung S, Sonntag KC, Andersson T, Bjorklund LM, Park JJ, Kim DW, Kang UJ, Isacson O, Kim KS. Genetic engineering of mouse embryonic stem cells by
Nurr1 enhances differentiation and maturation into dopaminergic neurons. Eur J Neurosci. 2002;16(10):1829-38.

11. Kim JY, Koh HC, Lee JY, Chang MY, Kim YC, Chung HY, Son H, Lee YS, Studer L, McKay R, Lee SH. Dopaminergic neuronal differentiation from rat embryonic neural precursors by Nurr1 overexpression. J Neurochem. 2003;85(6):1443-54.

12. Lee JY, Chang MY, Park CH, Kim HY, Kim JH, Son H, Lee YS, Lee SH. Ascorbateinduced differentiation of embryonic cortical precursors into neurons and astrocytes. J Neurosci Res. 2003;73(2):156-65.

13. Shin DM, Ahn Jl, Lee KH, Lee YS, Lee YS. Ascorbic acid responsive genes during neuronal differentiation of embryonic stem cells. Neuroreport. 2004;15(12):1959-63.

14. Volpicelli F, Consales C, Caiazzo M, Colucci-D'Amato L, Perrone-Capano C, di Porzio U. Enhancement of dopaminergic differentiation in proliferating midbrain neuroblasts by sonic hedgehog and ascorbic acid. Neural Plast. 2004;11(1-2):45-57.

15. Yu DH, Lee KH, Lee JY, Kim S, Shin DM, Kim JH, Lee YS, Lee YS, Oh SK, Moon SY, Lee SH, Lee YS. Changes of gene expression profiles during neuronal differentiation of central nervous system precursors treated with ascorbic acid. J Neurosci Res. 2004;78(1):29-37.

16. Lau T, Adam S, Schloss P. Rapid and efficient differentiation of dopaminergic neurons from mouse embryonic stem cells. Neuroreport. 2006;17(10):975-9.

17. Bagga V, Dunnet SB, Fricker-Gates RA. Ascorbic acid increases the number of dopamine neurons in vitro and in transplants to the 6-OHDA-lesioned rat brain. Cell Transplant. 2008;17(7):763-73.

18. Maciaczyk J, Singec I, Maciaczyk D, Nikkhah G. Combined use of BDNF, ascorbic acid, low oxygen, and prolonged differentiation time generates tyrosine hydroxylase-expressing neurons after long-term in vitro expansion of human fetal midbrain precursor cells. Exp Neurol. 2008;213(2):354-62.

19. Halliwell B. Vitamin C: antioxidant or pro-oxidant in vivo? Free Radic Res. 1996;25(5):439-54

20. Jomova K, Valko M. Advances in metal-induced oxidative stress and human disease. Toxicology. 2011;283(2-3):65-87.

21. Mandl J, Szarka A, Bánhegyi G. Vitamin C: update on physiology and pharmacology. Br J Pharmacol. 2009;157(7):1097-110.

22. Chen $\mathrm{L}, \mathrm{He} \mathrm{DM}$, Zhang $\mathrm{Y}$. The differentiation of human placenta-derived mesenchymal stem cells into dopaminergic cells in vitro. Cell Mol Biol Lett. 2009;14(3):528-36.

23. Horschitz S, Meyer-Lindenberg A, Schloss P. Generation of neuronal cells from human peripheral blood mononuclear cells. Neuroreport. 2010;21(3):185-90.

24. Yang J, Wang X, Wang Y, Guo ZX, Luo DZ, Jia J, Wang XM. Dopaminergic neuronal conversion from adult rat skeletal muscle-derived stem cells in vitro. Neurochem Res. 2012;37(9):1982-92.

25. Finkel T. Signal transduction by reactive oxygen species. J Cell Biol. 2011;194(1):7-15.

26. Rharass T, Lemcke H, Lantow M, Kuznetsov SA, Weiss DG, Panáková D. Ca² ${ }^{+}$-mediated mitochondrial reactive oxygen species metabolism augments Wnt/ß-catenin pathway activation to facilitate cell differentiation. J Biol Chem. 2014;289(40):27937-51.

27. Song JH, Shin SH, Ross GM. Prooxidant effects of ascorbate in rat brain slices. J Neurosci Res. 1999:58(2):328-36.

28. Song JH, Shin SH, Ross GM. Oxidative stress induced by ascorbate causes neuronal damage in an in vitro system. Brain Res. 2001;895(1-2):66-72.

29. Quievryn G, Messer J, Zhitkovich A. Carcinogenic chromium(VI) induces cross-linking of vitamin C to DNA in vitro and in human lung A549 cells. Biochemistry-US. 2002;41(9):3156-67.

30. Yen GC, Duh PD, Tsai HL. Antioxidant and pro-oxidant properties of ascorbic acid and gallic acid. Food Chem. 2002;79(3):307-13.

31. Aruoma O, Halliwell B, Gajewski E, Dizdaroglu M. Copper-ion-dependent damage to the bases in DNA in the presence of hydrogen peroxide. Biochem J. 1991;273(Pt 3):601-4.

32. Satoh K, Sakagami H. Effect of metal ions on radical intensity and cytotoxic activity of ascorbate. Anticancer Res. 1997;17(2A):1125-9.

33. Valko M, Leibfritz D, Moncol J, Cronin MTD, Mazur M, Telser J. Free radicals and antioxidants in normal physiological functions and human disease. Int J Biochem Cell B. 2007;39(1):44-84

34. Donato R, Miljan EA, Hines SJ, Aouabdi S, Pollock K, Patel S, Edwards FA, Sinden JD. Differential development of neuronal physiological responsiveness in two human neural stem cell lines. BMC Neurosci. 2007:8:36.

35. Haack F, Lemcke H, Ewald R, Rharass T, Uhrmacher AM. Spatio-temporal model of endogenous ROS and raft-dependent WNT/beta-catenin signaling 
driving cell fate commitment in human neural progenitor cells. PLoS Comput Biol. 2015;11(3):e1004106.

36. Mazemondet $\mathrm{O}$, Hübner R, Frahm J, Koczan D, Bader BM, Weiss DG, Uhrmacher AM, Frech MJ, Rolfs A, Luo J. Quantitative and kinetic profile of Wnt/B-catenin signaling components during human neural progenitor cell differentiation. Cell Mol Biol Lett. 2011;16(4):515-38.

37. Funato $Y$, Michiue $T$, Asashima M, Miki H. The thioredoxin-related redoxregulating protein nucleoredoxin inhibits Wnt- $\beta$-catenin signaling through Dishevelled. Nat Cell Biol. 2006;8(5):501-8.

38. Funato $\mathrm{Y}$, Miki $\mathrm{H}$. Redox regulation of Wnt signalling via nucleoredoxin. Free Radic Res. 2010;44(4):379-88.

39. Gao C, Chen YG. Dishevelled: the hub of Wnt signaling. Cell Signal. 2010;22(5):717-27.

40. Kalyanaraman B, Darley-Usmar V, Davies KJA, Dennery PA, Forman HJ, Grisham MB, Mann GE, Moore K, Roberts LJ 2nd, Ischiropoulos H. Measuring reactive oxygen and nitrogen species with fluorescent probes: challenges and limitations. Free Radic Biol Med. 2012;52(1):1-6.

41. Qian J, Yao B, Wui C. Fluorescence resonance energy transfer detection methods: sensitized emission and acceptor bleaching. Exp Ther Med. 2014;8(5):1375-80.

42. Pietraszewska-Bogiel A, Gadella TW. FRET microscopy: from principle to routine technology in cell biology. J Microsc-Oxford. 2011;241(2):111-8.

43. van Rheenen J, Langeslag M, Jalink K. Correcting confocal acquisition to optimize imaging of fluorescence resonance energy transfer by sensitized emission. Biophys J. 2004;86(4):2517-29.

44. Swindle EJ, Hunt JA, Coleman JW. A comparison of reactive oxygen species generation by rat peritoneal macrophages and mast cells using the highly sensitive real-time chemiluminescent probe pholasin: inhibition of antigeninduced mast cell degranulation by macrophage-derived hydrogen peroxide. J Immunol. 2002;169(10):5866-73.

45. Spagnuolo G, D'Antò V, Cosentino C, Schmalz G, Schweikl H, Rengo S. Effect of $\mathrm{N}$-acetyl-L-cysteine on ROS production and cell death caused by HEMA in human primary gingival fibroblasts. Biomaterials. 2006;27(9):1803-9.

46. Roskams AJl, Cai X, Ronnet GV. Expression of neuron-specific beta-III tubulin during olfactory neurogenesis in the embryonic and adult rat. Neuroscience. 1998;83(1):191-200.

47. Stambolic V, Ruel L, Woodgett JR. Lithium inhibits glycogen synthase kinase-3 activity and mimics wingless signalling in intact cells. Curr Biol. 1996;6(12):1664-8.

48. He TC, Sparks AB, Rago C, Hermeking H, Zawel L, da Costa LT, Morin PJ, Vogelstein B, Kinzler KW. Identification of C-MYC as a target of the APC pathway. Science. 1998;281(5382):1509-12.

49. Bartsch C, Bekhite MM, Wolheim A, Richter M, Ruhe C, Wissuwa B, Marciniak A, Müller J, Heller R, Figulla HR, Sauer H, Wartenberg M. NADPH oxidase and eNOS control cardiomyogenesis in mouse embryonic stem cells on ascorbic acid treatment. Free Radic Biol Med. 2011;51(2):432-43.

50. Zhu Z, Kremer P, Tadmori I, Ren Y, Sun D, He X, Young W. Lithium suppresses astrogliogenesis by neural stem and progenitor cells by inhibiting STAT3 pathway independently of glycogen synthase kinase 3 beta. PLoS One. 2011;6(9):e23341.

51. Su H, Chu TH, Wu W. Lithium enhances proliferation and neuronal differentiation of neural progenitor cells in vitro and after transplantation into the adult rat spinal cord. Exp Neurol. 2007:206(2):296-307.

52. Su H, Zhang W, Guo J, Guo A, Yuan Q, Wu W. Lithium enhances the neuronal differentiation of neural progenitor cells in vitro and after transplantation into the avulsed ventral horn of adult rats through the secretion of brain-derived neurotrophic factor. J Neurochem. 2009;108(6): 1385-98.

53. Kaufmann L, Marinescu G, Nazarenko I, Thiele W, Oberle C, Sleeman J, Blattner C. LiCl induces TNF-a and FasL production, thereby stimulating apoptosis in cancer cells. Cell Commun Signal. 2011;9:15.

54. Ming M, Wang S, Wu W, Senyuk V, Le Beau MM, Nucifora G, Qian Z. Activation of Wnt/B-catenin protein signaling induces mitochondria-mediated apoptosis in hematopoietic progenitor cells. J Biol Chem. 2012;287(27):22683-90.

55. Delneste $Y$, Jeannin P, Potier L, Romero P, Bonnefoy JY. N-acetyl-L-cysteine exhibits antitumoral activity by increasing tumor necrosis factor a-dependent T-cell cytotoxicity. Blood. 1997;90(3):1124-32.

56. Qanungo S, Wang M, Nieminen AL. N-acetyl-L-cysteine enhances apoptosis through inhibition of nuclear factor-kB in hypoxic murine embryonic fibroblasts. J Biol Chem. 2004;279(48):50455-64.
57. Tobwala S, Khayyat A, Fan W, Ercal N. Comparative evaluation of Nacetylcysteine and $\mathrm{N}$-acetylcysteineamide in acetaminophen-induced hepatotoxicity in human hepatoma HepaRG cells. Exp Biol Med. 2015:240(2):261-72.

58. Si F, Ross GM, Shin SH. Glutathione protects PC12 cells from ascorbate- and dopamine-induced apoptosis. Exp Brain Res. 1998;123(3):263-8.

59. Vera JC, Rivas Cl, Velásquez FV, Zhang RH, Concha II, Golde DW. Resolution of the facilitated transport of dehydroascorbic acid from its intracellular accumulation as ascorbic acid. J Biol Chem. 1995;270(40):23706-12.

60. Witenberg B, Kalir HH, Raviv Z, Kletter Y, Kravtsov V, Fabian I. Inhibition by ascorbic acid of apoptosis induced by oxidative stress in HL-60 myeloid leukemia cells. Biochem Pharmacol. 1999;57(7):823-32.

61. Kalcheim C, Leviel V. Stimulation of collagen production in vitro by ascorbic acid released from explants of migrating avian neural crest. Cell Differ. 1988:22(2):107-14.

62. Kim SH, Turnbull J, Guimond S. Extracellular matrix and cell signalling: the dynamic cooperation of integrin, proteoglycan and growth factor receptor. J Endocrinol. 2011;209(2):139-51.

63. Halliwell B. Oxidative stress in cell culture: an under-appreciated problem? FEBS Lett. 2003:540(1-3):3-6.

\section{Submit your next manuscript to BioMed Central and we will help you at every step:}

- We accept pre-submission inquiries

- Our selector tool helps you to find the most relevant journal

- We provide round the clock customer support

- Convenient online submission

- Thorough peer review

- Inclusion in PubMed and all major indexing services

- Maximum visibility for your research

Submit your manuscript at www.biomedcentral.com/submit
) Biomed Central 